\title{
TWO CONCEPTS OF RATIONALITY
}

\author{
DANNY FREDERICK ${ }^{*}$
}

\section{Introduction}

no Person can disobey Reason, without giving up his Claim to be a rational Creature

-Swift $(1726,261)$

RATIONALITY IS ESSENTIALLY connected with norms. In Western philosophy, while there has been much disagreement over what the norms of rationality are, there seems to have been substantial agreement that these norms are narrowly prescriptive; in fact there is a pronounced tendency to see rationality as leaving the agent no scope for choice in matters of thought, belief, inference and behaviour. On this pervasive view, rationality dictates: either one accepts, believes, infers or does what rationality says one should, or one is irrational. I will argue that this authoritarian concept of rationality is absurd. I contrast it with a libertarian concept of rationality, derived from the critical rationalism of Karl Popper. I argue that, while this approach avoids the absurdities of the authoritarian one, it requires some further development. To keep the discussion within a reasonable compass, after outlining the two concepts with regard to both theoretical and practical rationality, I discuss them critically with respect to theoretical rationality only; the comparison with respect to practical rationality is left for another occasion. However, as the distinction between theoretical and practical rationality is somewhat artificial, parts of the following discussion will inevitably cross over into some matters of practical rationality.

It would be impossible, as well as tiresome, to consider here every species within the authoritarian genus, so I will outline the full-blown authoritarian approach and illustrate it with a few examples from contemporary philosophy. I am challenging the underlying principles of that approach, so the application of my critique to other examples should be

*Danny Frederick (danny.frederick@,btinternet.com) is an independent researcher.

Cite THIS ARTICle AS: Danny Frederick, “Two Concepts of Rationality," Libertarian Papers 2, 5 (2010). OnLINE AT: libertarianpapers.org. THIS ARTICLE IS subject to a Creative Commons Attribution 3.0 License (creativecommons.org/licenses). 
reasonably straightforward, though it is not the case that every part of the critique will apply to every species of authoritarian rationalism. Further, as my purpose here is an overview, I do not pursue the arguments against authoritarian rationalism in great detail, considering all the possible responses and counter-responses; but I think I say enough to impugn the coherence of that view.

In section 2, I set out the main tenets of the authoritarian approach, with quotations from a few of the multitude of its contemporary philosophical exponents. In section 3, I suggest that, given what we know about human knowledge, the authoritarian concept of theoretical rationality generates a number of absurdities. In section 4, I expound the libertarian approach which derives from Popper. In section 5, I argue that, while Popper's approach to theoretical rationality avoids the absurdities of the authoritarian one, it requires three significant modifications to be made fully consistent. I conclude the discussion in section 6.

\section{The Authoritarian Approach}

Responsible believers and desirers are orthonomous subjects, in the sense that they recognize certain yardsticks of right belief and right desire and can respond to the demands of the right in their own case

-Pettit and Smith $(1996,442)$

Since ancient times, Western philosophers have propounded views according to which reason leads a person to beliefs that he must have or to actions that he must perform, if he is rational (Popper 1972b; 1983, 11-34; Bartley 1984, 169-83 and passim). In contemporary analytic philosophy the dominant views are still that, in matters of knowledge, rationality dictates what to believe and what to infer, and that, in practical matters, it dictates what action to perform or intend or desire; but some of the dictates may be relativised to other beliefs, values, desires or intentions of the person concerned.

Thus, it is said, for some simple propositions of logic and mathematics, to understand them is to know that they are true, or for some simple rules of inference, to understand them is to be disposed to infer in accord with them, perhaps because they are 'implicit definitions' of the logical or mathematical constants they contain. Non-simple propositions and rules of inference can then be established a priori by deductions exemplifying the simple rules of inference from the simple propositions and from non-simple propositions already inferred in this way (for variations on this theme see Boghossian 1996, BonJour 1998 and Peacocke 2005). For example, anyone who understands the concept of conjunction knows that a proposition of the form 
' $p$ and $q$ ' entails the corresponding proposition of the form ' $p$ ' (the rule of conjunction elimination). So, anyone who doubts the validity of an inference exemplifying such a simple rule cannot understand the concept of conjunction. Similarly, anyone who doubts one of the simple propositions of logic or mathematics simply does not understand the constituent concepts; or, if he does, he can only be irrational.

Further, not only is rationality supposed to dictate what logical and mathematical truths to believe and what principles of inference to use, it is also supposed to require, at least where the conclusion matters to us (Broome 2008 , 153), that we draw logically valid inferences, so that, from given beliefs or intentions, a person is rationally required to infer specific other beliefs or intentions. Thus, in a statement typical of many contemporary philosophers, Broome says (2002, 95):

When one proposition implies another (and the implication is immediate and obvious), believing the one requires you to believe the other...If you intend an end, and believe some act is a necessary means to it, your intention and belief normatively require you to intend the means.

As he makes clear (2008), he takes these requirements to be requirements of rationality.

In empirical matters rationality is supposed to be similarly prescriptive, dictating that we hold true or believe the best explanation (Harman 1965, 89; Smith 2004, 82-84). To circumvent the problem that the best explanation of a segment of empirical evidence may be inconsistent with other empirical evidence, this requirement may be transmuted into the Carnap-Hempel 'requirement of total evidence' to 'give your credence to the hypothesis supported by all available relevant evidence' (Davidson 1982, 38-41). As this is supposed to be a requirement of rationality, one who does not believe the explanation that is best, given all the available relevant evidence, is irrational (Davidson 1982, 41). Since a particular thinker might not know all the available relevant evidence, this principle of rationality may be relativised to the total evidence that the thinker accepts (Feldman 2000, 687-91). Either way, rationality leaves us no choice, at least so long as there is a best explanation: believe the best explanation or you are irrational.

The actions or intentions, and even the desires, of rational agents do not escape rationality's direction: 'there are norms governing what agents should desire and do at any moment' (Pettit and Smith 1996, 436). Thus, Davidson converted the 'requirement of total evidence' into a 'principle of continence' to provide a rational requirement for action: 'perform the action judged best on the basis of all available relevant reasons' (Davidson 1982, 41). 
Korsgaard summarises the position (1996, 320):

The necessity, or the compellingness, of rational considerations... may lie in the fact that, when they do move useither in the realm of conviction or in that of motivation-they move us with the force of necessity. But it will still not be the case that they necessarily move us...[because] a person may be irrational...

On the full-blown authoritarian view, then, rationality issues specific requirements about what we should believe, infer, intend, desire or do under specific conditions. There are various a priori propositions, including some of logic and mathematics that, rationally, we must believe if we understand them. There are various empirical theories that, rationally, we must believe because they provide the best explanation of some range of phenomena. There is a multitude of inferences we must, rationally, make; and, as a consequence, there is a multitude of beliefs and intentions that we must, rationally, have if we have (or retain) other beliefs and intentions. There are even desires that we must rationally have if we have other desires or if we have particular values. We are rationally required to perform the right or the best action in the circumstances; or, at least, we are rationally required to perform that action that is right or best according to our own values or desires. If we are rational, then, it seems we have very little scope to do anything other than what rationality dictates: any deviation from the rationally prescribed path is a mark of irrationality. As Pettit and Smith put it (1996, 444), without a trace of irony:

If an agent believes or desires rightly according to the evidence and the values, then there will be nothing attractive in itself about being such that he could have believed or desired otherwise. Believing or desiring otherwise will simply be a matter of his getting it wrong, and so doing much worse than he actually did...freedom is a person's ability, in the event of getting things wrong, to get them right.

\section{The Absurdities of the Authoritarian Approach}

a new theory, however special its range of application, is seldom or never just an increment to what is already known. Its assimilation requires the reconstruction of prior theory and the reevaluation of prior fact

—Kuhn $(1970,7)$

In conjunction with what we know about the growth of knowledge, the authoritarian concept of empirical knowledge leads to absurdities. First, it would hamper the growth of knowledge. For, one who believes a theory or accepts it as true and then devotes his energies to developing a theory that is 
inconsistent with it seems, if not plain irrational, at least to be committing himself to an activity that he views as having no prospect of success. Yet the great advances in our empirical knowledge have been theories that were inconsistent with the previously best explanation. For example, in the early sixteenth century, the Aristotelian-Ptolemaic theory was the best explanation of terrestrial and celestial motions (Kuhn 1957; Feyerabend 1975). If everyone had been rational according to the authoritarian concept, they would all have believed this theory or accepted it as true, and this would surely have inhibited the development of a heliocentric theory to replace it. In the late seventeenth century, the best explanation of planetary motion was Kepler's, while the best explanation of bodies falling to earth was Galileo's. If he had accepted these best explanations as true, it seems Newton would have had little incentive to set out to construct a better one which contradicted and replaced both (Popper 1983, 139-44). Newton's theory was accepted by scientists for the best part of two centuries as the best explanation of terrestrial and celestial motion. If Einstein had accepted this best explanation as true, or believed it, as required by the authoritarian concept of rationality, it would seem perverse that he should have set to work on relativity theory, which contradicted Newton's theory and eventually replaced it. The authoritarian approach would seriously inhibit major advances in our knowledge and would thus frustrate what it is intended to promote, which seems absurd.

Second, since each advance in our knowledge, each best explanation, is appropriately regarded as a temporary stopping point until something better is developed, the authoritarian view requires us to believe what it is reasonable to doubt, which seems absurd. The authoritarian may be able to evade this apparent absurdity by maintaining that a person may believe a theory with a moderate degree of belief that leaves room for doubt. I do not find the notion of degrees of belief coherent; but as discussion of that would require a separate paper I will not press this objection here.

Third, the authoritarian view would require us to believe what we believe to be impossible. For example, when it was proposed, Kepler's theory provided the best explanation of the motions of the heavenly bodies, but it offered no explanation of motions on earth. The best explanation of motions on earth at that time was given by Aristotelian physics augmented by medieval impetus theory. Both were good explanations, but they were plainly inconsistent with each other, since the former stated that the earth is in absolute motion and the latter stated that the earth is at absolute rest (Kuhn 1957; Feyerabend 1975, 69-161). Similarly, in the late-eighteenth century, the oxygen theory was the best explanation of weight relations in chemical reactions while the conflicting phlogiston theory was the best explanation for 
why the properties of metals contrasted with the properties of the ores from which they were formed (Kuhn 1977, 323). A policy of believing the best explanation, then, would often require us to believe a conjunction which we believe cannot be true, which is absurd.

The authoritarian requirement might be modified to avoid this absurdity by requiring that, where there is a conflict between best explanations, only the better explanation should be believed. But where explanations concern different ranges of phenomena, they are likely to be incommensurable, since they explain different things. Further, where comparisons of explanatory merit can be made, the result will be to eliminate some best explanations as candidates for belief, thus weakening the requirement to believe the best explanation. Indeed, given the common occurrence of such explanatory conflicts the requirement will be substantially weakened. Alternatively, the requirement could be modified so that belief is required only where best explanations do not contradict each other; but this will weaken the requirement further and could even leave it empty; and a requirement that requires nothing seems absurd. This is also the fate of the 'requirement to believe the hypothesis supported by all available relevant evidence,' if it is taken literally and so does not mean merely 'the bestsupported hypothesis given all the available evidence' (in which case it would be the same as the requirement to believe the best explanation). For, no scientific theory is supported by all available relevant evidence. Every scientific theory is faced with an abundance of counterexamples and the task for researchers is to develop auxiliary theories to try to overturn them (Kuhn 1970, 23-42; Feyerabend 1975, 55-68). For example, even the Ptolemaic theory, with its ad hoc armoury of epicycles, eccentrics and equants, could achieve only approximate consistency with observed celestial motions (Kuhn 1957, 59-73), and it was inconsistent with the observed quantitative variations in the brightness of the planets (Feyerabend 1975, 109-11, 14143).

The authoritarian view might be defended by maintaining that we are rationally required to believe only the explanation that is really best, rather than that which is at any time evaluated as best. Here, 'really best' must mean something like the best that we can ever achieve. But no matter how good an explanation we manage to achieve at any time, it is always possible, for all we can know, that a better and conflicting theory will be proposed in future. We will therefore be rationally required to believe a theory that we can never be in a position to identify and which might not even exist as yet. As this is something it is impossible to do, it is absurd to maintain that we are rationally required to do it. 
Another possible defence would be to say that scientific theories are merely instruments: each best explanation applies where and only where it works, so best explanations cannot conflict. But such instruments are not possible objects of belief. If someone is to believe Kepler's theory, he must believe what it says, including that the earth is in absolute motion; and if he is to believe the Aristotelian theory, he must believe what it says, including that the earth is at absolute rest.

The authoritarian approach also generates absurdities with regard to our knowledge of logic and mathematics. First, it claims that there are some propositions such that to understand them is to know that they are true. But Russell's paradox showed that the most 'self-evident' propositions could be inconsistent: Frege's apparently self-evident fifth axiom, that for every property there is a set of things to which it applies (possibly the empty set), entails that, corresponding to the property of not being an element of itself, is the set of all those sets which are not elements of themselves. But if that set is an element of itself, it must have the property of not being an element of itself, which is a contradiction; yet if it is not an element of itself then, by virtue of having that property, it must be an element of itself, which is a contradiction. The set both is, and is not, an element of itself. Whitehead and Russell $(1927,59)$ concluded:

Infallibility is never attainable, and therefore some element of doubt should always attach to every axiom and to all its consequences. In formal logic, the element of doubt is less than in most sciences, but it is not absent, as appears from the fact that the paradoxes followed from premises which were not previously known to require limitations.

If an argument is valid, then there is a necessarily true conditional which takes the conjunction of the premises as antecedent and the conclusion as consequent. So the element of doubt that must always attach to the conditional must always attach to the validity of the argument. Thus, the authoritarians' supposed 'implicit definitions' of logical or mathematical constants in terms of the propositions they make true or the inferences they make valid could, for all we can know, involve latent contradictions. It is therefore open to a rational person who understands the constants to doubt whether the propositions are true or the inferences valid. This has, indeed, been shown by the development of a variety of non-standard logics in recent decades: every significant principle of inference has been impugned in one or other of them, such as double negation in intuitionist logic, modus ponens in some fuzzy logics, and conjunction elimination in connexive logic (Priest and Thomason 2007, 96-98). Thus, understanding cannot by itself yield 
knowledge of either truth or validity (for more detailed arguments see Williamson 2003, 2006).

Second, since it is open to a rational person to question the validity of any inference, no matter how 'immediate and obvious' it may appear to be, it follows that it is false that he is irrational if he does not believe or intend the 'immediate and obvious' implications of his beliefs or intentions. We can note, parenthetically, that one who questions the validity of what is in fact a valid inference does not thereby contradict himself. For example, if he believes premises of the forms ' $p$ ' and 'if $p$, then $q$ ' but questions whether the corresponding proposition of the form ' $q$ ' follows, he need not believe the corresponding proposition of the form 'not- $q$.' He may instead suspend judgement. Further, even someone who believes a contradiction need not thereby knowingly contradict himself, since he might not believe, or he might even sincerely deny, that what he believes is self-contradictory. This was the case with Frege when developing an axiomatisation of arithmetic before Russell's discovery of the paradox.

Third, it seems absurd to maintain that the edifice of mathematical knowledge is obtained by simple deductions from indubitable propositions (Lakatos 1976, 1978a, 1978b). After the discovery of Russell's paradox, apparently indubitable axioms had to be amended and supplemented by axioms which were far from indubitable, such as Russell's ramified theory of types or von Neumann's distinction between class and set. As Russell says (1956, 325):

When pure mathematics is organised as a deductive system-i.e. as the set of all those propositions that can be deduced from an assigned set of premises - it becomes obvious that, if we are to believe in the truth of pure mathematics, it cannot be solely because we believe in the truth of the set of premises. Some of the premises are much less obvious than some of their consequences, and are believed chiefly because of their consequences.

Some of these non-obvious premises (such as a theory of logical or linguistic types) may be hidden from view by being built into the formation rules for formulae of the logical or mathematical system. This may help to create a false impression that the (explicit) premises of the axiomatic system are indubitable.

The full-blown authoritarian concept of rationality tries to narrow down rational choice as far as possible. But its 'rational requirements' for theoretical rationality, which attempt to prescribe what must be believed a priori and empirically and what must be inferred, generate multiple absurdities. This is so if these 'rational requirements' are taken to be deontological, because what they require of us, at least at times, is absurd, 
such as, to believe what we believe to be impossible or to believe a theory that we can never identify. And the requirements are absurd if they are taken to be consequentialist, because they frustrate the aims they are intended to promote, by requiring us to believe or accept the currently-best explanations as well as propositions and inferences that merely appear to us at the moment to be indubitable.

\section{The Libertarian Approach}

orthodoxy is the death of knowledge, since the growth of knowledge depends entirely on the existence of disagreement

-Popper $(1994,34)$

The libertarian approach to rationality is less familiar than the authoritarian one, so I will explain it in more detail (in this section, all parenthetical references are to works of Popper unless otherwise specified). The version I present here reflects the best of Popper's sometimes conflicting views, with some contributions from Bartley and Lakatos. It combines the basic idea of rationality, that it is rational to use suitable ways of achieving our objectives, with the rationalist idea that arguments are suitable ways of finding solutions to our problems. The term 'rationalist' here is not opposed to 'empiricist,' since arguments include 'arguments from experience' (1966, 224 25, 228; 1972a, 49, 52-53; 1972c, 50-52; 1972f, 221-22; 1994, 60-61). The libertarian approach differs from the authoritarian in giving painstaking attention to our inescapable fallibility and limitations. Thus, first, it recognises that the rationalist idea goes beyond the basic idea of rationality. For we might deny that argument is a suitable means for finding solutions to our problems, for example, if it could be shown that argument leads inevitably to paradoxes. Thus irrationalism need not be irrational: rationalism is a conjecture about rationality that is open to criticism (1966, 227-31; Bartley 1984, 109-36, 247-60). Second, it replaces justificational arguments, which attempt to establish or justify a theory, with critical arguments, which attempt to compare rival theories and rate them as better or worse (1983, 19-20; 1994, 60; Bartley 1984, 169-183). Third, it offers no prescriptions about what to hold true, believe, accept or infer, or what actions to perform, intend or desire. Instead, it sees rationality as exhibited in questioning, criticising, conjecturing, testing, experimenting and improving. In consequence, it entails that the authoritarian view is mistaken in construing theoretical rationality as being concerned with belief.

In attempting to identify suitable ways of achieving an objective, an often useful first step is to clarify the objective. In our pursuit of knowledge our objective is to find solutions to problems (1972a, 106). With respect to 
theoretical knowledge, the primary solutions are explanatory theories. The problems usually arise from our discovery of an inconsistency, either within the jumble of our existing theories or expectations, or between these existing theories and some new experience (1972f, 222). Thus the growth of knowledge begins with the criticism of our inherited theories and the proposal of new ones. Our inherited theories come partly from biological evolution, in which case they are incorporated into our sensory equipment or are instinctive expectations; and partly from our culture, in which case they are handed down by tradition (1972c, 46-52; 1972d; 1994, 40-43, 58-59; Popper and Eccles 1977, 45-46, 91-92, 132-35, 261-71, 513-515).

As our aim is knowledge, a true explanatory theory is plainly preferable to a false one. Unfortunately, we have no way of telling whether an explanatory theory is true. We do not posses the power to see into nature a priori, so every explanatory theory has to be tested against the world as we experience it. But any finite set of observation statements is consistent with an infinity of explanatory theories, so even if a theory is consistent with all known observation statements, it may still be false (1972a, 27-34, 266 and passim). Further, we have no way of telling whether an explanatory theory is false, for two reasons. First, observation statements inevitably involve interpretations which may be false. For example, 'Here is a glass of water' implies that the receptacle will exhibit the law-like behaviour of glass and that its contents will behave in the law-like way that water does; and these implications may be inconsistent with other observation statements (1972a, 94-95). So when there is an inconsistency between a theory and an observation statement, it may be the latter that is false. Second, it is almost always the case that, when we subject a theory to test, a limited (but sometimes quite large) number of theories belonging to 'background knowledge' are used in the derivation of testable consequences. So, if the test result is negative, it may be the background knowledge, rather than the theory under test, which is at fault. Since truth and falsity will not serve, we need some other way of rating one explanatory theory as better than another.

Although we can never know that any observation statement is true, we can often get agreement between people about which observation statements to accept for the time being. This is especially so in science, where observations are often made as a result of controlled experiments which can be repeated by any number of competent people (1972a, 104-105). For this reason, socially agreed public observation statements, though all are fallible and some may later be rejected, play a vital role in Popper's proposed assessment of explanatory theories. Popper proposes that an explanatory theory should be evaluated in terms of a set of explanatory merits, including that: it is falsifiable, that is, in conjunction with suitable background 
knowledge, it contradicts some possible observation statements; it solves the problems it was designed to solve; it proceeds from a unifying idea; it is selfconsistent; it is consistent with agreed observation statements; it entails new falsifiable predictions some of which contradict some of those of rival explanations; it corrects, and thus explains, the corroborated regularities of currently accepted theories; and it is a survivor of attempted falsifications (1972a, 39, 40-42, 82-86, 86-87, 108-109, 123, 253n*2; 1972f, 217-20, 24145; 1983, 29-30, 139-45).

Our objective in the pursuit of knowledge should be to obtain better explanations, where one explanation is better than a rival insofar as it exemplifies more of these explanatory merits or exemplifies them more fully. As the most suitable means of achieving our objective, Popper proposes that we adhere to a number of 'methodological rules.' Although these rules are tailored to the case of scientific knowledge, they apply also, though perhaps with less rigour, to the more commonplace kinds of knowledge to be found in government, business and everyday life (1961, 55-104; 1972a, 15; 1972f, 216), and also-when testability is generalised to criticisability-to metaphysics (1976, 150-51; 1983, 80-88). Unlike the authoritarian conception, Popper's rules do not concern what propositions to believe or to accept as true. To bring out this contrast, and to avoid the confusion that so often besets critics of Popper, I will talk of instating propositions. When we instate a proposition, we label it as the best we have for the time being; so there is no tension between instating a proposition while simultaneously seeking assiduously for another proposition with better explanatory merits which, if found, will oust the currently-instated proposition (that is, be instated in its stead). Popper's rules include the following:

(i) instate observation statements that are inter-subjectively agreed (1972a, 93-111);

(ii) instate existing background knowledge (1972f, 238-39);

(iii) do not instate any new theory unless it is inter-subjectively testable (1972a, 27, 44-48, 56);

(iv) do not start developing a theory without having a problem to solve (1972a, 277; 1972f, 222);

(v) try to generate new universal theories and develop them into a falsifiable form (1972a, 31-32, 54, 276-78);

(vi) check theories for consistency (1972a, 32);

(vii) think up potential falsifying observation statements and ways of securing uncoerced agreement to them, such as experimental tests (1972a, 32-33, 280); 
(viii) carry out the experiments and other tests to try to falsify the explanatory theory or theories (1972a, 32-33, 54, 280);

(ix) instate an explanatory theory only if it has greater explanatory merit than its rivals (1972a, 53-54, 78-84);

(x) never regard any statement as justified, as established beyond the need for further testing (1972a, 53, 54);

(xi) avoid 'ad hoc manoeuvres,' that is, attempts to save a theory from refutation by fabricating, suppressing or simply ignoring the results of experiments or observations, or by simply re-defining terms or attributing a negative test result to some of the background knowledge that was used in deriving the prediction from the theory (1972a, 78-84; 1972d, 240-42).

Rule (xi) is implicit in the other rules to the extent that a theory saved by an ad hoc manoeuvre will thereby have its explanatory merit reduced and will thus be liable to compare unfavourably to a rival theory, if not immediately, at least as testing proceeds and as new theories are developed. But the rule is worth stating separately because ad hoc manoeuvres come naturally to us but frustrate our objective of obtaining better explanations. However, the rejection of ad hoc ways of saving a theory is not a rejection of all ways of doing so. For example (Kuhn, 1957, 261-62), when, in the midnineteenth century, the observed motions of Uranus conflicted with the predictions of Newton's theory, scientists amended background knowledge to posit the existence of another planet with just the properties necessary to account for Uranus' anomalous motions in terms of Newton's theory. But this was not ad hoc, because the change to background knowledge had a novel falsifiable prediction, that a new planet would be seen at a certain time and place in the sky; and this prediction survived testing (Neptune was discovered). Thus, if a theory is contradicted by an instated observation statement, we can try to save the theory by seeking changes to background knowledge that not only remove the contradiction but also entail novel falsifiable predictions that are not in turn refuted (1972a, 53-54, 82-84; 1976, 41-44).

A similar situation occurs where the inconsistency is not between a theory and an instated observation statement but within the theory itself. We can reject the theory outright; or, if the theory is fruitful or seems promising, continue to work with the theory despite the self-contradiction provided that we acknowledge that the inconsistency is a defect that we intend ultimately to remove in a non-ad-hoc way. In physics this happened with quantum theory, which made its early progress on inconsistent foundations (Lakatos 1970, 140-54). In mathematics it happened with the calculus: Berkeley rejected it 
because it was inconsistent; but Newton and others lived with the inconsistency because the theory was very fruitful; and eventually the inconsistency was removed (1983, 266-71).

Such temporary acceptance of inconsistency, either within a theory or between a theory and other propositions that we accept, does not amount to believing an inconsistency or to accepting that an inconsistency is true, because instating a theory does not amount to judging it true and does not commit us to believing it. Instating a theory is only ever provisional: the theory becomes part of the modified tradition that is handed down in future, to be subjected to new experiments, criticism, and competition from new theories or from improved old ones (1966, 245; 1972a, 123; 1972f, 222; 1976, 86; 1983, 33, 132-37; 1994, 40-43, 52-54, 58-61).

Axiomatic mathematical theories are like the theories of empirical science in that they are conjectures which are tested against the 'basic statements' of the discipline (Lakatos 1976, 1978a, 1978b). However, whereas scientific theories are tested against inter-subjectively agreed spatio-temporal observation statements, mathematical theories are tested against statements or theorems inter-subjectively agreed to be intuitively evident. But some of these 'basic statements' may be overturned by the progress of theory (for example, on grounds of simplicity) or by means of innovative thoughtexperiments, just as inter-subjectively agreed observation statements in science can be overturned when the theories they presuppose are rejected.

Similarly (Bartley 1984, 247-60), logic is an attempt to provide a theory of validity, and currently accepted axioms or rules of inference may be refuted. Thus, Aristotelian logic has been largely abandoned, various artificialities are introduced into modern logical systems to avoid the logical paradoxes; and further revisions are to be expected. However, rejection of some of our efforts to formulate logic does not amount to a rejection of logic itself, that is, the concept of deducibility. For, deducibility is presupposed by the very possibility of improvement through criticism, which depends on deductively valid arguments which transmit truth from premises to conclusion (are truth-preserving) and retransmit falsity from the conclusion to the conjunction of the premises. We must retain the concept of deducibility through all revisions to logic if we are to remain rationalists.

It should be clear that on the libertarian approach, the growth of knowledge requires freedom of thought and speech and will be fostered by institutions and traditions that safeguard and encourage open criticism (1961, 152-59; 1972a, 42, 54; 1972d; 1994). Unlike the authoritarian approach, the libertarian approach does not, therefore, attempt to impose uniformity on people who are seeking to contribute to the growth of knowledge. Rational 
researchers may pursue a multitude of different ways of finding an explanatory solution to the same problem; and even if everyone is agreed that a particular theory is currently the best explanation, some people may try to develop a rival theory which will eventually supersede it. Thus different people may be working on different theories; people working on the same theory may be trying to develop it in different ways; people who happen to be developing the same theory in the same way may, quite rationally, respond differently to a negative test result, with some giving up the theory and others not, and, among the latter, some pursuing falsifiable changes to one part of background knowledge and others pursuing falsifiable changes to other parts of background knowledge. Thus, theoretical rationality permits radical disagreement and diverse research programmes in attempts to solve the same or similar or overlapping problems (1972a, 76-77, including n2; 1983, 69-71).

This encouragement of diversity is not relativism (1994). Many, perhaps all, of our theories are false; and our appraisal of theories is intended to rank them, as better or worse, in terms of their explanatory merits. Of course, equally rational people may disagree about the rating of explanatory theories, because rival theories may exemplify different explanatory merits in different degrees, making comparisons unclear, and different people may weight the importance of the different merits differently (1972f, 218n3, 235; 1983, 6971). Further, we might amend the set of explanatory merits or emend the methodological rules intended to contribute to the growth of knowledge (Popper amplified and clarified these over time). Thus, the libertarian account of rationality is a conjecture upon which we may be able to improve as we learn more about the world or as the world changes. Rationality permits us to question, and to attempt to falsify, any theory, including those assumed in publicly agreed observation statements, including those which express supposedly fundamental principles of mathematics or logic, and including theories of rationality. There is nothing that theoretical rationality requires us to believe, accept or infer.

Popper did not offer a systematic account of practical rationality, but elements of a libertarian account can be found in his writings. Thus, just as rationality with regard to knowledge begins with inherited theories and seeks to improve them, so with regard to action it begins with biologically or culturally inherited ways of behaving, or traditions, and seeks to improve upon them (1972d, 131-32). Just as in science, we compare theories, so in action we compare options, with a view to rating them as better or worse $(1966,232-33)$. And just as in science the currently-best theory may soon be refuted, so in action the currently accepted view about which option is best may be refuted by the attempt to implement that option or one of its rivals 
(1972c, 56-57). Rationality is therefore silent about what specific actions we should do (or intend or desire): it is up to us.

\section{Criticism of the Libertarian Approach}

we cannot possibly conceive of a reason as being consciously directed from outside in regard to its judgements; for in that case the subject would attribute the determination of his power of judgement, not to his reason, but to an impulsion

- Kant $(1785,448)$

Popper's approach, which encourages questioning and improvement, avoids the absurdities entailed by the authoritarian view of empirical knowledge. This is hardly surprising, since it was tested and developed against what we know about the growth of scientific knowledge (Popper 1972a, 15, 27; 1972c, 33-39; 1976, 36-38). We can doubtless improve upon Popper's formulations, especially as our knowledge of the growth of knowledge grows; but this is in keeping with the fallibilist ethos of his approach. The libertarian approach also avoids the absurdities entailed by the authoritarian concept of logical and mathematical knowledge, which is, again, unsurprising, since the extension of the libertarian approach to mathematics was made by Lakatos in connection with his study of the growth of mathematical knowledge. However, it seems to me that, with regard to logical and mathematical knowledge, the libertarian approach requires two significant modifications.

First, the libertarian account allows that instated logico-mathematical theories and 'basic statements' can be overturned by intuitively evident thought experiments. Such thought experiments, if successful, show to be possible something that the instated proposition rules out as impossible. But once we acknowledge that there may turn out to be possible counterexamples to instated logical or mathematical propositions or rules of inference, we have to acknowledge that changes in our empirical knowledge could lead us to accept that such a counterexample is actual, in which case we will accept that those propositions or rules of inference are empirically refuted. This sort of thing has been seen in mathematics: for two millennia it was accepted as a truth of geometry that through one point exactly one parallel can be drawn to a given straight line, but for the past two centuries that proposition has been denied to be a truth of mathematics, and for the last century it has been denied to be a truth of physics. Therefore, not only can there be no analytic truths, that is, propositions that can be known to be true by any rational person who understands them, but there can be no a priori knowledge in the sense of knowledge that is immune to revision in the light of experience. Thus, while logic and mathematics are concerned with necessities, our knowledge of them is ultimately empirical, in the sense of being tested, 
ultimately, against instated observation statements (but not in the sense of being derived from or justified by experience).

This conclusion is similar to that of Quine (1953), though our argument is based simply on our fallibility and does not assume verificationism, radical meaning scepticism, or holism. The conclusion was not endorsed by Popper (1972e, 206-12), but it is implicit in Popper's epistemology, according to which our intuitions are shaped by the theories we take for granted (Popper and Eccles 1977, 43-46, 132-35; see also Papineau 2009 for a recent articulation of a very similar view). Intuitions of possibility, necessity and selfevidence therefore reflect the more ingrained theories, principally, theories we have inherited biologically or culturally (or sub-culturally). Since we start to learn, that is, to modify these theories, from an early age, entrenchment will be a matter of degree, which one would expect to be reflected in our feelings of self-evidence. This might be what underlay Quine's proposal to replace the analytic-synthetic distinction with a continuum. Of course, many, and perhaps all, of these inherited theories will be false, so we should try to review them critically and improve or replace them.

Second, we must also (and therefore) accept that we might even give up the principle of non-contradiction. Popper $(1966,39)$ and Bartley $(1984,251-$ 52) claimed that minimal logic, the idea of a valid argument, essentially involves the law of non-contradiction because, if we permit contradictions, then falsity cannot be retransmitted from conclusion to premises, so criticism becomes impossible. However, recent work in non-standard logic suggests that admitting the truth of some propositions of the form ' $p$ and not- $p$ ' might provide a simpler, less ad hoc and more comprehensive logical theory. In such a dialetheic logic, it is not the case that a contradiction entails everything; but a valid argument is still one that is truth-preserving. Further, accepting that some contradictions are true does not amount to admitting that they all are: the bulk of our arguments occur in consistent contexts, in which falsity may be retransmitted from conclusion to premises (Priest 2006). We might not want to go down the dialetheic route, but if we do, we can remain rationalists. We will then maintain that inconsistency is a good but not infallible indication of non-truth. Thus self-consistency, like all the other explanatory merits, will be such that its absence can in some cases be compensated by some other explanatory merits.

Finally, the libertarian approach requires clarification regarding the status of its methodological rules. For philosophers brought up in the authoritarian tradition, it will seem natural to interpret these rules as rational requirements, as dictates of reason. Popper does not explicitly address the question, though he does say that the rules are 'essentially somewhat flexible' $(1976,99)$. His methodological rules seem to be a pretty mixed bag. Some, 
particularly (v) and (vi), are flexible in the sense that they seem to be heuristic, that is, rule-of-thumb guides to be utilised at the researcher's discretion. But rules (i), (ii), (iii), (ix), (x) and (xi) appear to be either prescriptions or proscriptions, and thus inflexible. However, even the inflexible rules cannot be rational requirements. For it is always the case that the currently-best theory might be refuted in the next moment, so we cannot rationally be required to act on it $(1972 \mathrm{c}, 56-57)$, though we are rationally permitted to do so (1972a, 282; 1972c, 57; 1976, 228; 1983, 65); and this applies also where the theory in question is a theory of rationality. Thus the methodological rules of the libertarian account of rationality constitute advice which we are rationally permitted to impugn, just as a scientist is rationally permitted to attempt to refute the currently-best theory. Compliance with the methodological rules is therefore not a requirement of rationality. The libertarian rationalist may, in consistency, rationally try to replace his theory of rationality with a better one; indeed, such has been my aim in this section.

It might seem to follow that, on the libertarian concept of theoretical rationality, 'anything goes' (Feyerabend 1975, 23-28 and passim). But that is not so, for three reasons. First, the libertarian approach advocates argument as the best way of attempting to find solutions to our problems: one who sets out to refute the currently-best theory is constructing a counter-argument. In contrast, Feyerabend attempts a reductio ad absurdum of rationalism: he argues that argument is not, in general, a suitable way of finding solutions to our theoretical problems (1975, 187-96 and 209n77). Second, the libertarian account contains some well-thought-out advice about how to proceed rationally, even though it recognises that no advice can be binding for a rational agent. Third, intentionally self-frustrating behaviour, as may be exhibited in akrasia or psychopathology, is irrational because it violates the basic idea of rationality that one should choose suitable ways of achieving one's (overall) objectives. But a discussion of this third point must await the deferred consideration of practical rationality. If the argument of this paper is correct, then Feyerabend's argument is confused and his representation and his criticism of Popper are largely mistaken, although his criticism of Lakatos' philosophy of science seems largely just.

\section{Conclusion}

There is a place, and a function, within the critical method of science, even for the lunatic fringe

- Popper $(1983,70)$.

Human agents are customarily thought to be both free and capable of rationality. Yet the predominant tendency in Western philosophy sees 
rationality as a straightjacket which the free agent must don if he is to be rational. Rationality is conceived as requiring specific beliefs or as requiring specific beliefs given specific evidence, as justifying some beliefs a priori, as compelling specific inferences, and as commanding specific actions (or intentions or desires) or as requiring specific actions, intentions or desires given a set of propositional attitudes. The exponents of this approach want to justify beliefs or knowledge-claims or to justify actions or decisions; and some of them explicitly avow their conservatism (for example, Quine 1953 and Harman 1986). They seem to see rationality as a cudgel with which to compel conformity.

However, this authoritarian view is absurd. Its rational requirements for empirical knowledge would induce stagnation and would enjoin agents to believe things that they believe to be impossible or to believe a theory they cannot identify. Its requirements for a priori knowledge are just dogmatic, since: there can be no indubitable or rationally unchallengeable truths; only a neurotic would feel compelled to draw inferences (Popper 1972e, 207); and some of the premises of the supposedly a priori sciences of logic and mathematics are less obvious than their consequences. Its requirements for practical rationality can also be shown to lead to absurdities, but that will require a separate paper.

In contrast, the libertarian concept of rationality demands freedom: it sees rationality as exhibited in questioning and testing by agents who propose unjustified guesses which they expose to criticism; who seek to improve upon, rather than to protect, our extant knowledge; who experiment in both thought and action; and who decide and act without compulsion. Our best theory of rationality may contain some well-thought-out advice; but rationality permits us to try to refute it, even by acting against it. Rationality permits the widest experimentation and disagreement. All that is prohibited as irrational is intentional self-frustration. The libertarian rationalist will often seek to refute the dogmas that the authoritarian rationalists try to justify; indeed, he will often seek to refute his own (tentatively held) views.

\section{References}

Bartley, W.W. 1984. The Retreat to Commitment, second edition. London: Open Court.

Boghossian, Paul. 1996. 'Analyticity Reconsidered.' Nous, 30/3: 369-91. 
BonJour, Laurence. 1998. In Defense of Pure Reason. Cambridge: Cambridge University Press.

Broome, John. 2002. 'Practical Reasoning.' In Reason and Nature: Essays in the Theory of Rationality, ed. J. Bermùdez and A. Millar (85-111). Oxford: Oxford University Press.

—. 2008. 'Is Rationality Normative?' Disputatio, 11: 153-71.

Davidson, Donald. 1982. 'How is Weakness of the Will Possible?' In his Essays on Actions and Events, reprinted with corrections (21-42). Oxford: Clarendon Press.

Feldman, Richard. 2000. 'The Ethics of Belief.' Philosophy and Phenomenological Research, 60/3: 667-95.

Feyerabend, Paul. 1975. Against Method. London: New Left Books.

Harman, Gilbert. 1965. 'Inference to the Best Explanation.' Philosophical Review, 74/1: 88-95.

— 1986. Change in View. Cambridge, Mass.: MIT Press/Bradford Books.

Kant, Immanuel. 1785. Groundwork of the Metaphysic of Morals, tr. H. J. Paton in his (1948) The Moral Law: London: Hutchinson.

Korsgaard, Christine. 1996. 'Skepticism about Practical Reason.' In her Creating the Kingdom of Ends (311-34). Cambridge: Cambridge University Press.

Kuhn, Thomas. 1957. The Copernican Revolution. Cambridge, Mass: Harvard University Press.

- 1970. The Structure of Scientific Revolutions, second enlarged edition. Chicago: University of Chicago Press.

- 1977. 'Objectivity, Value Judgement, and Theory Choice.' In his The Essential Tension (320-39). Chicago: University of Chicago Press.

Lakatos, Imre. 1970. 'Falsification and the Methodology of Scientific Research Programmes.' In Criticism and the Growth of Knowledge, ed. I. Lakatos and A. Musgrave (91-196). London: Cambridge University Press.

- 1976. Proofs and Refutations. Cambridge: Cambridge University Press. . 1978a. 'Infinite Regress and Foundations of Mathematics.' In his 1978c (3-23). 
1978b. 'A Renaissance of Empiricism in the Recent Philosophy of Mathematics?' In his 1978c (24-42)

-1978c. Mathematics, Science and Epistemology, ed. J. Worrall and G. Currie. Cambridge: Cambridge University Press.

Papineau, David. 2009. 'The Poverty of Analysis.' Aristotelian Society Supplementary Volume (forthcoming), downloaded on 23 November 2009 from: http://www.kcl.ac.uk/content/1/c6/04/17/78/ThePovertyofAnalysis sentendJan09.doc

Peacocke, Christopher. 2005. 'The A Priori.' In The Oxford Handbook of Contemporary Philosophy, ed. F. Jackson and M. Smith (739-63). Oxford: Oxford University Press.

Pettit, Philip and Michael Smith. 1996. 'Freedom in Belief and Desire.' The Journal of Philosophy, 93/9: 429-49.

Popper, Karl. 1961. The Poverty of Historicism, corrected edition. London: Routledge and Kegan Paul.

- 1966. The Open Society and its Enemies, Volume 2, fifth (revised) edition. London: Routledge and Kegan Paul Ltd

- 1972a. The Logic of Scientific Discovery, sixth impression (revised). London: Hutchinson.

- 1972b. 'On the Sources of Knowledge and of Ignorance.' In his $1972 \mathrm{~g}(3-30)$.

- 1972c. 'Science: Conjectures and Refutations.' In his 1972g (33-65).

. 1972d. 'Towards a Rational Theory of Tradition.' In his 1972g (120$35)$.

. 1972e. 'Why are the Calculi of Logic and Arithmetic Applicable to Reality?' In his 1972g (201-14).

-1972f. 'Truth, Rationality, and the Growth of Scientific Knowledge.' In his 1972g (215-50).

- 1972g. Conjectures and Refutations, fourth (revised) edition. London: Routledge and Kegan Paul.

- 1976. Unended Quest. Glasgow: Collins.

-1983. Realism and the Aim of Science. London: Routledge.

. 1994. 'The Myth of the Framework.' In his The Myth of the Framework (33-64). London: Routledge. 
Popper, Karl and John Eccles. 1977. The Self and its Brain. London: SpringerVerlag.

Priest, Graham. 2006. In Contradiction, second edition. Oxford: Oxford University Press.

Priest, Graham and Neil Thomason. 2007. '60\% Proof.' Australasian Journal of Logic, 5: 89-100.

Russell, Bertrand. 1956. 'Logical Atomism.' In Logic and Knowledge, ed. R. Marsh (321-43). London: George Allen and Unwin.

Quine, W. V. O. 1953. 'Two Dogmas of Empiricism.' In his From a Logical Point of View (20-46). Cambridge, Mass: Harvard University Press.

Smith, Michael. 2004. 'Humean Rationality.' In The Oxford Handbook of Rationality, ed. A. Mele and P. Rawling (75-92). Oxford: Oxford University Press.

Swift, Jonathan. 1726. Gulliver's Travels, ed. Claude Rawson (2005). Oxford: Oxford University Press.

Whitehead, Alfred and Bertrand Russell. 1927. Principia Mathematica, Volume 1, second edition. Cambridge: Cambridge University Press.

Williamson, Timothy. 2003. 'Understanding and Inference.' Proceedings of the Aristotelian Society, Supplementary Volume 77: 249-93.

Supplementary Volume 80: 1-41. 